Ana Halas*

UDK: 811.111'367.623:811.163.41'367.623:[81'37+159.9]

Odsek za anglistiku

$81 ' 362$

Filozofski fakultet

DOI: $10.19090 /$ gff.2017.1.99-115

Univerzitet u Novom Sadu

Originalni naučni rad

\title{
METAFORIČKA ZNAČENJA ENGLESKOG PRIDEVA HARD I SRPSKOG PRIDEVA TVRD - KOGNITIVNOLINGVISTIČKA ANALIZA**
}

\begin{abstract}
Analiza predstavljena u ovom radu podrazumeva identifikaciju pojmovnih metafora aktivnih $\mathrm{u}$ semantičkoj disperziji engleskog prideva hard i srpskog prideva tvrd. Cilj analize je poređenje metaforičkih obrazaca i njihove produktivnosti u semantičkim strukturama dva analizirana prideva, a time i sticanje uvida u sličnosti i razlike između engleskog i srpskog jezika u pogledu konceptualizacije apstraktnijih pojmova pomoću pojma fizičkog svojstva tvrdoće. Rezultati izvršene analize pokazuju da postoji značajan broj pojmovnih metafora zajedničkih za semantičke strukture prideva hard i tvrd, odnosno utvrđen je skup apstraktnih ili manje konkretnih domena koji se konceptualizuju pomoću domena tvrdoće i u engleskom, i u srpskom jeziku. Međutim, pomenuti zajednički pojmovni obrasci nisu jednako produktivni u semantičkim strukturama dva prideva, a takođe utvrđeni su i slučajevi u kojima su na osnovu istog pojmovnog obrasca izvedena različita značenja u dvema strukturama.
\end{abstract}

Ključne reči: pojmovna metafora, domen tvrdoće, metaforički obrazac, polisemična struktura, semantička disperzija, metaforičko značenje, engleski jezik, srpski jezik.

\section{UVOD}

Polisemična disperzija jedne lekseme rezultat je različitih semantičkih transformacija među kojima se, kao vrlo produktivan tip, izdvaja metafora. Kognitivna lingvistika posmatra metaforu kao stvar mišljenja i organizacioni princip našeg pojmovnog sistema, pa stoga i uvodi termin pojmovna metafora. Pomoću pojmovne metafore uspešno je objašnjena semantika mnogih leksičkih kategorija u kognitivističkoj literaturi (Klikovac, 2004: 30).

S obzirom na to da se fizička svojstva predmeta često javljaju kao izvorni domeni u obrascima pojmovnih metafora, može se pretpostaviti da je i svojstvo tvrdoće poslužilo kao izvorni domen za razumevanje različitih apstraktnijih

\footnotetext{
*ana.halas@ff.uns.ac.rs

** Ovaj rad je napisan u okviru projekta Jezici i kulture u vremenu i prostoru (178002), koji finansira Ministarstvo prosvete, nauke i tehnološkog razvoja Republike Srbije.
} 
pojmova kako u engleskom, tako i u srpskom jeziku, te je opravdano očekivati i to da su polisemične strukture prideva hard i tvrd, koji primarno označavaju dato fizičko svojstvo, bogate metaforičkim značenjima.

Analiza predstavljena u ovom radu podrazumeva identifikaciju pojmovnih metafora aktivnih u semantičkoj disperziji prideva hard i tvrd, kao i poređenje semantičkih struktura dva prideva u pogledu utvrđenih metaforičkih obrazaca i njihove produktivnosti. Cilj analize je utvrđivanje stepena poklapanja metaforičkih obrazaca aktiviranih u semantičkoj disperziji dva prideva odnosno iznalaženje sličnosti i razlika između dva jezika u pogledu konceptualizacije apstraktnih pojmova polazeći od pojma fizičke tvrdoće kao izvornog domena. U slučaju postojanja metaforičkih obrazaca zajedničkih za semantičku disperziju dva prideva, utvrdiće se i stepen poklapanja značenja izvedenih na osnovu datih obrazaca u okviru dveju semantičkih struktura.

$\mathrm{S}$ obzirom na to da je pojam fizičke tvrdoće utemeljen u našem opštem telesnom iskustvu, u ovom radu polazi se od pretpostavke da postoji visok stepen sličnosti između engleskog i srpskog jezika u pogledu konceptualizacije apstraktnijih pojmova polazeći od pomenutog izvornog. U skladu s tim, očekivani ishod analize predstavljene u ovom radu jeste utvrđivanje metaforičkih obrazaca koji su zajednički za semantičku disperziju dva prideva. Međutim, aktivacija istih metaforičkih odnosa ne mora nužno značiti i njihovu jednaku produktivnost $u$ dvama jezicima, a, takođe, mogući su i slučajevi izvođenja sasvim različitih značenja u dvema polisemičnim strukturama na osnovu zajedničkog obrasca.

\section{METAFORA KAO MEHANIZAM POLISEMIJE}

Polisemija podrazumeva sposobnost lekseme da ima više značenja koja su sva međusobno motivisano povezana (Cruse, 2011: 108). Sva značenja jedne lekseme čine njenu polisemičnu strukturu (Gortan-Premk, 2004: 38). Ona se sastoji od osnovnog ili primarnog značenja i sekundarnih značenja (Dragićević, 2010: 131-132). Pomenuta motivisana povezanost značenja posledica je činjenice da je svako značenje izvedeno od osnovnog ili nekog drugog značenja u datoj strukturi putem određenog semantičkog mehanizma, a jedan od najčešće aktiviranih je leksička metafora. Ona je osnovni proces u formiranju značenja reči (KnowlesMoon, 2006: 3). Leksička metafora je jezički mehanizam čije delovanje podrazumeva prenos imena s jednog pojma na drugi na osnovu uočene sličnosti (Dragićević, 2010: 148).

Međutim, kako bi se u potpunosti razumela suština leksičke metafore neophodno je znati činjenicu da je ovaj jezički mehanizam zapravo zasnovan na 
mehanizmu mišljenja, pojmovnoj metafori, koju u središte pažnje lingvističke istraživačke delatnosti postavljaju Lakoff i Johnson (1980). Pojmovna metafora predstavlja razumevanje apstraktnog pojma ili domena pomoću drugog iskustveno bližeg, konkretnijeg ili čulno saznatljivog pojma ili domena (Klikovac, 2004: 12). Tako, na primer, apstraktniji domen vremena razumevamo pomoću nama iskustveno bližeg domena novca (npr. Potrošili smo toliko vremena a ništa nismo uradili, Ako sve pripremim večeras, uštedeću malo vremena), domen života pomoću domena putovanja (npr. Svašta ga je zadesilo na njegovom životnom putu), domen rasprave pomoću domena rata (npr. Pitam se kako li će odbraniti svoje stavove) itd. Ovaj mehanizam je asimetričan, jer se ciljni domen o kome imamo manje znanja povezuje sa izvornim domenom o kome je naše znanje veće (Stanojević, 2013: 83). Zapravo, pojmovna metafora predstavlja preslikavanje između domena odnosno iz izvornog (konkretnijeg) u ciljni (apstraktni) domen (Lakoff i Johnson, 2014: 289). Između elemenata data dva domena uspostavlja se niz korespondencija (Gentner i Bowdle, 2008: 109). Preslikavanje strukture izvornog domena odnosno njegovih elemenata na strukturu odnosno elemente ciljnog domena možemo pokazati na primeru pojmovne metafore LJUBAV JE PUTOVANJE ilustrovane rečenicom We're at a crossroads (Na raskršću smo) upotrebljenoj pri opisu situacije u kojoj se moraju doneti važne odluke u ljubavnoj vezi (Kövecses, 2010: 6). Ovaj primer pokazuje kako se elementi izvornog domena putovanja preslikavaju na elemente ciljnog domena ljubavi tako da putnici predstavljaju ljubavnike, putovanje događaje u vezi, a raskrsnica trenutak u vezi u kome se mora napraviti izvestan izbor. Značaj mehanizma pojmovne metafore potvrđuje i zapažanje o tome da je opisani način govorenja o ljubavi i ljubavnim vezama uobičajen i u svakodnevnoj jezičkoj upotrebi (Evans-Green, 2006: 294). Ovo možemo potvrditi brojnim primerima, poput: Gledaj dokle smo stigli, Možemo li krenuti ispočetka?, Pronašli su izlaz iz krize, itd. (Klikovac, 2004: 13).

Izvorni domeni su u najužoj vezi sa našim svakodnevnim telesnim iskustvom u kome ključnu ulogu igra naša čulna percepcija. Na primer, u slučaju sinestezijsko-metaforičkog prenosa značenja kod prideva u engleskom i srpskom jeziku, domen dodira (kome pripada i ovde istraživani pojam fizičkog svojstva tvrdoće jer ga percepiramo taktilno) najčešći je izvorni domen kako u engleskom, tako i u srpskom jeziku, odnosno čulo dodira ima veliki značaj za strukturiranje značenja (Komaromi, 2016: 178). Dakle, nije redak slučaj da se u ulozi izvornog domena nađu i svojstva entiteta poput boje, veličine, težine, oštrine, itd, što je posebno uočljivo kod prideva koji primarno označavaju kakvo fizičko svojstvo poput sledećih primera iz srpskog jezika: visok, nizak, tvrd, oštar, topao, hladan, itd. Na primer, među značenjima prideva visok koja nudi Rečnik srpskohrvatskoga 
književnog jezika Matice srpske (1967-1976) nalaze se i 'koji je izuzetan po kakvoći' (npr. visok kvalitet), 'pohvalan, laskav' (npr. visoka ocena), 'ugledan, otmen' (npr. visoki društveni krugovi). Svako od njih izvedeno je od osnovnog značenja, koje se odnosi na fizičko svojstvo posedovanja znatnog rastojanja između donje i gornje tačke, i to putem metafore IZUZETAN/POVOLJAN U RAZLIČITOM SMISLU JE VISOK. Na osnovu datog primera uviđamo da je izvedeno novo značenje prideva visok tako što je izvršen prenos imena s jednog pojma na drugi na osnovu obrasca po kome se ono što je izuzetno u različitom smislu poima kao nešto što ima visinu u fizičkom smislu. Dakle, na delu je mehanizam razumevanja apstraktnog pojma pomoću pojma koji je utemeljen u našem fizičko-prostornom iskustvu. Isti metaforički obrazac aktivan je i u semantičkoj strukturi prideva high u engleskom jeziku, što vidimo na osnovu sledećih značenja koja nudi Oxford Dictionary of English (2. izdanje, 2005): 'very favourable' (npr. a high opinion of someone), 'great in rank, status, or importance' (npr. a high position in an organization/institution). Navedeni primer potvrđuje da se na osnovu izvesnog metaforičkog obrasca, i to polazeći od značenja koje se odnosi na određeni segment fizičko-prostornog iskustva govornika kao izvornog domena, konceptualizuje izvesni apstraktni pojam, odnosno izvodi se novo značenje. Drugim rečima, posredstvom metafore konstruišemo novi pojam od starog, već postojećeg (Bartsch, 2002: 73). U kognitivnoj semantici ustaljena je distinkcija doslovno nasuprot metaforičkom, a koja je očigledna i u slučaju prideva koji označavaju fizička svojstva, te čije je primarno značenje doslovno odnosno ono predstavlja primarni pojam zasnovan na našem čulnom iskustvu od koga se putem metafore izvode ostala značenja (Rakova, 2003: 33).

Reč je onoliko polisemična koliko ima različitih ciljnih pojmova sa kojima se izvorni pojam, očitovan u osnovnom, doslovnom značenju, povezuje (Kövecses, 2010: 214). Dakle, metafora je kognitivna veza između dva ili više značenja polisemične lekseme, $\mathrm{s}$ tim da ove metafore postoje nezavisno u našem pojmovnom sistemu, a aktiviraju se pri proširenju značenja reči (Kövecses, 2010: 216). Značaj pojmovne metafore kao mehanizma polisemije u engleskom i srpskom jeziku potvrđen je i rezultatima studija autorki: Prodanović-Stankić (2009), Radić-Bojanić i Halupka-Rešetar (2014), Halupka-Rešetar i Radić-Bojanić (2015) i dr. 


\section{ANALIZA METAFORIČKIH ZNAČENJA PRIDEVA HARD I TVRD}

Pridevi hard i tvrd imaju bogatu polisemičnu strukturu u kojoj značajan udeo imaju upravo metaforička značenja, a koja su za potrebe ove analize ekscerpirana, u slučaju prideva hard, iz rečnika: Collins English Dictionary (11. izdanje), Merriam-Webster Collegiate Dictionary (11. izdanje) i Oxford Dictionary of English (2. izdanje), a u slučaju prideva tvrd iz: šestotomnog Rečnika srpskohrvatskoga književnog jezika Matice srpske (1967-1976) i jednotomnog Rečnika srpskoga jezika Matice srpske (2007). Konsultovani su i različiti rečnici i popisi metafora.

Prvi korak u analizi podrazumevao je utvrđivanje pojmovnog obrasca na osnovu koga je svako posmatrano metaforičko značenje izvedeno. U slučaju oba prideva, uočen je niz slučajeva u kojima je na osnovu jednog metaforičkog obrasca izvedeno nekoliko značenja. Stoga je izvršeno grupisanje onih značenja koja su izvedena aktivacijom iste pojmovne metafore. Potom je usledilo poređenje aktiviranih metaforičkih obrazaca i njihove produktivnosti u semantičkoj disperziji prideva hard i tvrd, koji primarno označavaju fizičko svojstvo tvrdoće, što se zaključuje i pregledom njihovih rečničkih članaka u kojima su prvo navedena sledeća značenja: 'solid, firm, and rigid; not easily broken, bent, or pierced' (Oxford Dictionary of English, 2. izdanje) i 'koji (usled čvrste zbijenosti čestica) pruža jak otpor prodoru sečiva i drugih alatki' (Rečnik srpskoga jezika Matice srpske, 2007).

Rezultati ovako postavljene analize prikazani su tabelarno. Za svaki identifikovani metaforički odnos formirana je zasebna tabela u čijoj su levoj koloni prikazana značenja prideva hard, a u desnoj prideva tvrd izvedena na osnovu predstavljenog obrasca, čime se omogućava jasan uvid u njegovu produktivnost. U slučaju zajedničkih obrazaca, značenja prideva hard i tvrd koja se poklapaju barem delimično prikazana su u istom redu u tabeli. Prazno polje u tabeli pokazuje da $\mathrm{u}$ datom jeziku ne postoji značenje analiziranog prideva koje korespondira sa odgovarajućim značenjem drugog posmatranog prideva predstavljenim u istom redu u tabeli. U tabelama 8, 9 i 10, sva polja u jednoj od kolona su prazna, jer je reč o obrascima koji su produktivni u semantičkoj disperziji samo jednog od dva analizirana prideva. Stoga, prazna kolona pokazuje da $u$ polisemičnoj strukturi posmatranog prideva ne postoji nijedno značenje izvedeno na osnovu predstavljenog obrasca. 
Tabela 1: Metaforički odnos MENTALNO/FIZIČKI NAPORAN JE TVRD i značenja izvedena na osnovu njega u semantičkoj strukturi prideva hard i tvrd

\begin{tabular}{|l|l|}
\hline \multicolumn{2}{|c|}{1 MENTALNO/FIZIČKI NAPORAN JE TVRD } \\
\hline $\begin{array}{l}\text { - requiring physical effort (e.g. hard } \\
\text { work, hard graft, } \text { hard slog) }\end{array}$ & \\
\hline $\begin{array}{l}\text { - difficult to bear or endure (e.g. hard } \\
\text { times, hard life, hard conditions, } \text { a hard } \\
\text { blow) }\end{array}$ & $\begin{array}{l}\text { - koji je ispunjen naporima, težak, } \\
\text { mukotrpan (npr. tvrd život, tvrd zanat, } \\
\text { tvrde godine) }\end{array}$ \\
\hline $\begin{array}{l}\text { - done with a lot of force or strength } \\
\text { (e.g. } \text { a hard blow, a hard whack, a hard } \\
\text { slap, a hard run, a hard shove) }\end{array}$ & \\
\hline $\begin{array}{l}\text { - difficult to understand or solve (e.g. } a \\
\text { hard question, hard problems, } \text { a hard } \\
\text { concept } \text { ) }\end{array}$ & \\
\hline
\end{tabular}

Obrazac MENTALNO/FIZIČKI NAPORAN JE TVRD je čak četvorostruko produktivan u semantičkoj disperziji prideva hard. Zapravo, ovaj metaforički odnos je i najproduktivniji u izvođenju značenja datog prideva. S druge strane, u slučaju posmatranog prideva srpskog jezika, produktivnost ove metafore je vrlo mala, jer je na osnovu nje izvedeno svega jedno značenje, ali koje se, pak, poklapa sa jednim od četiri pomenuta značenja prideva hard. U pitanju je značenje 'mukotrpno, teško', a najčešće se pridevom hard odnosno tvrd upotrebljenim u ovom značenju opisuju život, vremena ili uslovi (života, rada i sl). Međutim, u engleskom jeziku, poimanje nečega što zahteva fizički napor kao objekta koji poseduje svojstvo tvrdoće poslužilo je kao osnova za izvođenje još dve upotrebe prideva hard, koje su, u prethodno pomenutim rečnicima, identifikovane kao dva zasebna značenja. Tako se ovim pridevom opisuje posao koji je fizički naporan (npr. hard work, hard graft), ali i jak udarac ili šamar koji zahteva ulaganje fizičke snage (npr. a hard blow, a hard slap, a hard whack, a hard shove). Dakle, probijanje površine tvrdog predmeta zahteva fizički napor, a na osnovu analiziranih metaforičkih značenja, uočavamo da

\footnotetext{
${ }^{1} \mathrm{Na}$ osnovu uvida u odgovarajuće definicije ponuđene u pomenutim rečnicima, izvedene su i formulisane jezgrovite definicije značenja prideva hard odnosno tvrd, koje su predstavljene u tabeli, a koje sadrže samo ključnu specifičnu komponentu određenog značenja na osnovu koje se ono razlikuje od ostalih metaforičkih značenja datog prideva. Ponuđeni primeri preuzeti su iz rečnika koji su korišćeni za ekscerpciju značenja. U slučaju pojedinih značenja, rečnici nude samo jedan primer upotrebe, zbog čega su ona i u tabelama potkrepljena samo jednom ilustracijom.
} 
se taj deo telesnog iskustva koristi u srpskom, a naročito $u$ engleskom jeziku za poimanje i drugih situacija koje iziskuju naprezanje ljudskog tela. U engleskom jeziku, apstraktniji pojam mentalnog napora takođe se konceptualizuje pomoću domena tvrdoće. Stoga, kompleksno pitanje ili problem, koji kao takav zahteva ulaganje mentalnog napora onoga koji pokušava da na njega odgovori odnosno da ga reši, govornici engleskog jezika porede sa tvrdim predmetom. Na osnovu iskustva vezanog za ulaganje fizičkog napora pri probijanju površine onoga što je tvrdo razumeva se i situacija u kojoj je neophodno uložiti mentalni napor da bi se došlo do suštine problema ili pitanja. Ovo je sasvim jasan primer povezivanja sfere fizičkog sa sferom mentalnog, odnosno razumevanja apstraktnijeg pojma pomoću određenog aspekta telesnog iskustva. Na osnovu prethodne analize, zaključujemo da je povezivanje domena fizičkog odnosno mentalnog napora sa domenom fizičkog svojstva tvrdoće znatno inventivnije iskorišćeno u semantičkoj strukturi prideva hard $\mathrm{s}$ obzirom na broj i raznolikost značenja izvedenih njegovom aktivacijom.

Tabela 2: Metaforički odnos MENTALNO/ FIZIČKI JAK JE TVRD i značenja izvedena na osnovu njega u semantičkoj strukturi prideva hard i tvrd

\begin{tabular}{|l|l|}
\hline \multicolumn{2}{|c|}{ 2. MENTALNO/ FIZIČKI JAK JE TVRD } \\
\hline $\begin{array}{l}\text { - free of weakness, tough (e.g. } a \text { hard } \\
\text { player, hard people, } \text { a hard man) }\end{array}$ & $\begin{array}{l}\text { - koji je dobre fizičke izdržljivosti (npr. } \\
\text { tvrd čovek) }\end{array}$ \\
\hline $\begin{array}{l}\text { - resistant to stress or disease (e.g. } a \\
\text { hard plant) }\end{array}$ & $\begin{array}{l}\text { - koji se dobro odupire nečemu, otporan } \\
\text { (npr. tvrd od zime, tvrd od smrti) }\end{array}$ \\
\hline & $\begin{array}{l}\text { - brojan i dobro naoružan (npr. } \text { tvrda } \\
\text { straža) }\end{array}$ \\
\hline
\end{tabular}

Obrazac koji je gotovo jednako produktivan u semantičkim strukturama prideva hard i tvrd je MENTALNO/ FIZIČKI JAK JE TVRD. Mentalnu sliku predmeta koji poseduje svojstvo tvrdoće, te koji kao takav odoleva udarcima, savijanju, prodoru sečiva i sl, govornici ova dva jezika povezuju sa animatnim subjektom koji je izdržljiv i otporan na okolnosti koje ga ugrožavaju, poput stresa, bolesti, napada i sl. Kako se u tabeli vidi, ovaj obrazac je dvostruko produktivan u semantičkoj strukturi engleskog prideva, te trostruko u strukturi srpskog prideva, a od toga dva značenja ovih prideva se delimično poklapaju. Kada je reč o značenju izvedenom konceptualizacijom ljudske izdržljivosti pomoću pojma tvrdoće, u srpskom jeziku, ciljni pojam podrazumeva isključivo fizičku izdržljivost, dok u engleskom jeziku on može uključivati i mentalnu izdržljivost. U značenju 'otporan', pridev hard može opisivati sve animatne referente, što nije slučaj sa pridevom tvrd koji se u ovom 
značenju odnosi samo na ljude. U svom trećem značenju izvedenom na osnovu pomenutog obrasca, pridev tvrd se koristi u specifičnom kontekstu u kome opisuje odbrambene grupe, te je otpornost u ovom slučaju rezultat dobre naoružanosti ili velike brojnosti. Ovakvu upotrebu ne nalazimo u semantičkoj strukturi prideva hard.

Tabela 3: Metaforički odnos BEZOSEĆAJAN/EMOTIVNO BEZIZRAŽAJAN JE TVRD i značenja izvedena na osnovu njega u semantičkoj strukturi prideva hard i tvrd

\begin{tabular}{|l|l|}
\hline \multicolumn{2}{|c|}{ 3. BEZOSEĆAJAN/EMOTIVNO BEZIZRAŽAJAN JE TVRD } \\
\hline $\begin{array}{l}\text { - lacking sympathy or kindness (e.g. } a \\
\text { hard landlord, } \text { a hard look, hard voice, } \\
\text { a hard taskmaster) }\end{array}$ & $\begin{array}{l}\text { - neosetljiv, nemilosrdan, okrutan (npr. } \\
\text { tvrda duša) }\end{array}$ \\
\hline & $\begin{array}{l}\text { - uzdržljiv u ispoljavanju osećanja (npr. } \\
\text { tvrdo srce) }\end{array}$ \\
\hline & $\begin{array}{l}\cdot \text { koji izražava strogost, hladnoću (npr. } \\
\text { tvrdo lice, } \text { tvrd pogled) }\end{array}$ \\
\hline & $\begin{array}{l}\text { - krut, uštogljen (npr. tvrda kretnja, } \\
\text { tvrda versifikacija) }\end{array}$ \\
\hline
\end{tabular}

Konceptualizacija bezosećajnosti ili emotivne bezizražajnosti pomoću pojma fizičke tvrdoće odlikuje oba posmatrana jezika, mada je metaforički obrazac kojim se dati izvorni i ciljni domen povezuju (BEZOSEĆAJAN/EMOTIVNO BEZIZRAŽAJAN JE TVRD) značajno produktivniji u srpskom nego u engleskom jeziku. Ovo je zapravo najproduktivnija metafora u semantičkoj strukturi prideva tvrd. Govornici oba jezika bezosećajnost ili okrutnost poimaju pomoću svojstva fizičke tvrdoće, a najčešći referenti koji se usled ovakve konceptualizacije opisuju kao tvrdi su: osoba, pogled, duša itd. U engleskom jeziku, samo se potpuno nepostojanje (sa)osećajnosti poima pomoću fizičkog svojstva tvrdoće. Međutim, u srpskom jeziku, odsustvo emocija je u svojim različitim vidovima povezano sa fizičkim svojstvom tvrdoće. Stoga je, na osnovu date povezanosti, izveden širi opseg suptilnije izdiferenciranih značenja. Tako se u srpskom jeziku i neispoljavanje osećanja, koje ne znači nužno i njihovo nepostojanje, razumeva pomoću pojma tvrdoće. U semantičkoj strukturi prideva tvrd postoje još dva značenja koja se odnose na neispoljavanje osećanja, ali u specifičnom kontekstu tako da se u prvom slučaju ono tumači kao strogost (npr. tvrd pogled, tvrdo lice), a u drugom kao krutost (npr. tvrda kretnja). 
Tabela 4: Metaforički odnos POUZDAN JE TVRD i značenja izvedena na osnovu njega u semantičkoj strukturi prideva hard i tvrd

4. POUZDAN JE TVRD

- reliable, based on truth (e.g. hard facts, $\quad$ - pouzdan, siguran (npr. tvrd dokaz) hard evidence, hard news, hard information, hard proof)

- dealing with verifiable facts (e.g. hard science, a hard subject)

Sledeći pojam koji se kako u engleskom, tako i u srpskom jeziku konceptualizuje pomoću pojma tvrdoće je pouzdanost. U umu govornika oba jezika, ono što je zasnovano na činjenicama ili istinitosti, pa se kao takvo smatra pouzdanim, razumeva se kao entitet koji se odlikuje tvrdoćom ili koji je teško oštetiti ili uništiti. Značenje izvedeno ovakvom konceptualizacijom postoji u semantičkoj strukturi oba posmatrana prideva, mada se pridev hard upotrebljava sa širim opsegom uobičajenih referenata kojima pripadaju činjenice, dokazi, vesti, informacije, dok u srpskom jeziku pridev tvrd upotrebljen $\mathrm{u}$ ovom značenju uobičajeno kolocira sa imenicom dokaz. U engleskom jeziku, na isti se način konceptualizuje i varijacija pojma pouzdanosti koja se javlja u specifičnom, naučnom kontekstu, a očitovana je u značenju koje se odnosi na zasnovanost na proverljivim činjenicama, pa i nauka ili određeni predmet razmatranja mogu biti opisani kao tvrdi.

Tabela 5: Metaforički odnos POSTOJAN JE TVRD i značenja izvedena na osnovu njega u semantičkoj strukturi prideva hard i tvrd

\section{POSTOJAN JE TVRD}

- high and unlikely to change (e.g. hard prices, hard commodities, hard assets, hard shares)

- nepokolebljiv (npr. tvrda odluka, tvrda reč, tvrda namera, tvrda nada)

- tvrdoglav, uporan (npr. tvrda glava)

Metaforički obrazac koji je aktiviran u semantičkoj disperziji oba analizirana prideva, ali na osnovu koga su u engleskom i srpskom izvedena različita značenja, je POSTOJAN JE TVRD. Povezivanje apstraktnijeg domena postojanosti sa konkretnijim domenom tvrdoće ostvareno je na osnovu sličnosti koja se ogleda u nepromenjivosti koju postojanost podrazumeva, ali je poseduje i tvrdi predmet koji 
odoleva spoljnim silama koje nastoje da ga na određeni način deformišu savijanjem, probijanjem i sl. Međutim, pojam postojanosti konceptualizovan na objašnjeni način na različite se načine konkretizuje u engleskom i srpskom jeziku. Jedino značenje prideva hard izvedeno na osnovu datog obrasca upotrebljava se $u$ kontekstu kupoprodajnih odnosa, pa se, na primer, cene koje su visoke i stalne opisuju kao tvrde. S druge strane, ovaj obrazac je dvostruko produktivan u srpskom jeziku, a jedna od njegovih konkretizacija očitovana je u značenju nepokolebljivosti identifikovanom na osnovu specifičnosti referenata poput odluke, reči, namere i sl. Druga konkretizacija ovog obrasca u srpskom jeziku takođe je uslovljena specifičnošću referenta, a to je glava osobe koja je uporna, odlučna i postojanih namera, te koja se, stoga, opisuje kao tvrda.

Tabela 6: Metaforički odnos NOSILAC IZRAŽENE KARAKTERISTIČNE OSOBINE JE TVRD i značenja izvedena na osnovu njega u semantičkoj strukturi prideva hard i tvrd

6. NOSILAC IZRAŽENE KARAKTERISTIČNE OSOBINE JE TVRD

- denoting an extreme faction within a political party (e.g. the hard left, a hard left framework, a hard right faction)

- koji u vrlo velikoj meri sadrži karakteristiku pojma označenog imenicom uz koju stoji (npr. tvrda sirotinja)

Obrazac NOSILAC IZRAŽENE KARAKTERISTIČNE OSOBINE JE TVRD je takođe zajednički za semantičke strukture dva prideva, ali, kao i u prethodnom slučaju, sasvim različita značenja su na osnovu njega izvedena u engleskom i srpskom jeziku. Izraženost karakteristične osobine nečega govornici oba jezika konceptualizuju polazeći od fizičkog svojstva tvrdoće kao izvornog pojma. U engleskom jeziku, značenje izvedeno posredstvom ove pojmovne metafore uslovljeno je vrlo specifičnim, političkim kontekstom tako da je tipični referent politička frakcija, a karakteristična osobina koju on sadrži u visokom stepenu je ekstremnost u zastupanju sopstvenih ideja i stavova, pa se tako, na primer, ekstremna levica ili desnica opisuje kao tvrda. U srpskom jeziku, pak, značenje izvedeno na osnovu datog obrasca nije uslovljeno specifičnim kontekstom, te dozvoljava širok opseg mogućih referenata, mada se u konsultovanim rečnicima navodi samo jedan ilustrativni primer - tvrda sirotinja (žestoka, teška sirotinja). 
Tabela 7: Metaforički odnos VISOKO INTENZIVAN JE TVRD i značenja izvedena na osnovu njega u semantičkoj strukturi prideva hard i tvrd

\section{VISOKO INTENZIVAN JE TVRD}

- strongly alcoholic (e.g. hard liquor, hard spirits, hard alcohol, hard drink)

- very strong and addictive (e.g. hard drugs)

- highly penetrating (e.g. hard radiation, hard X-rays)

Ukoliko je nešto intenzivno, govornici oba jezika to opisuju kao tvrdo. Ipak, obrazac po kome se svojstvo visokog intenziteta poima pomoću svojstva tvrdoće znatno je produktivniji u semantičkoj disperziji prideva hard. Zapravo, ovaj obrazac leži u osnovi tri značenja čija je diferencijacija izvršena na osnovu specifičnosti njihovih referenata, a to su, u prvom slučaju, alkoholna pića, u drugom narkotici, a u trećem radijacija ili radioaktivni zraci. Sve navedene referente, ukoliko se odlikuju visokim intenzitetom, govornici engleskog jezika opisuju kao tvrde. Ipak, očigledno je da je opisana konceptualizacija primenjiva samo u vrlo ograničenom broju slučajeva u engleskom. U semantičkoj disperziji prideva tvrd, pojmovna metafora o kojoj je reč minimalno je produktivna, što znači da se prepoznaje u osnovi svega jednog značenja, koje je, pored toga, i vrlo usko definisano i identifikovano na osnovu jedinstvenog referenta, a to je san. Međutim, na osnovu formulacije definicije ovog značenja $u$ analiziranim rečnicima zaključujemo da se san visokog intenziteta ne konceptualizuje samo pomoću domena tvrdoće, već i domena čvrstine i dubine, pa se tako u srpskom jeziku san ne opisuje samo kao tvrd, već i kao čvrst ili dubok.

Tabela 8: Metaforički odnos FIZIČKI/MENTALNO NEPRIJATAN JE TVRD i značenja izvedena na osnovu njega u semantičkoj strukturi prideva hard

\section{FIZIČKI/MENTALNO NEPRIJATAN JE TVRD}

- harsh to the senses (e.g. hard light, hard noise, hard sunshine)

- (of weather) severe (e.g. hard winter, hard frost, hard weather, a hard rain)

- harsh, offensive, resentful (e.g. saying hard things) 
Poimanje onoga što izaziva fizičku ili mentalnu neprijatnost kao tvrdog objekta karakteristično je samo za govornike engleskog jezika. Na osnovu svog telesnog iskustva, govornici engleskog jezika znaju da neposredan kontakt sa tvrdom površinom naročito pod pritiskom, a svakako i udar o nju izaziva fizičku neprijatnost. Na osnovu sličnosti koja se ogleda u izazvanoj neprijatnosti, taj segment telesnog iskustva vezan za fizičko svojstvo tvrdoće preslikava se na domen nepovoljnih vremenskih prilika. Otuda se u engleskom jeziku pridevom hard opisuje zima, mraz, i sl. Pomenuto iskustvo vezano za svojstvo tvrdoće govornici engleskog jezika povezuju i sa neprijatnošću doživljenom čulom vida ili sluha. Neophodno je istaći da je u ovom slučaju na delu specifičan tip leksičke metafore pod nazivom sinestezija. Ona predstavlja metaforičko povezivanje domena jednog čula sa domenom nekog drugog čula, kao što je u datom primeru doživljaj iz sfere čula dodira kojim percepiramo tvrdoću povezan sa doživljajem čula vida i sluha (Dragićević, 2010: 151). Stoga, u engleskom jeziku imamo spojeve poput hard light ili hard noise u kojima je upotrebljen pridev koji primarno određuje pojmove iz sfere čula dodira. Naredno značenje je rezultat konceptualizacije mentalno ili emotivno neprijatnog pomoću svojstva tvrdoće. Dakle, ono što izaziva neprijatno osećanje, poput uvredljivih reči (npr. saying hard things to someone), poima se kao tvrdi objekat $i$ to na osnovu već objašnjenog telesnog iskustva vezanog za fizičku neprijatnost izazvanu kontaktom sa tvrdom površinom.

Tabela 9: Metaforički odnos ŠKRT JE TVRD i značenje izvedeno na osnovu njega u semantičkoj strukturi prideva tvrd

\begin{tabular}{|l|l|}
\hline $9 . \quad$ ŠKRT JE TVRD \\
\hline & $\begin{array}{l}\text { - preterano štedljiv (npr. } \text { tvrd na novcu, } \\
\text { tvrd na pomoći, tvrd na pari) }\end{array}$ \\
\hline
\end{tabular}

Pojmovne metafore aktivirane u semantičkoj disperziji samo prideva $t v r d$ su ŠKRT JE TVRD i BOGAT JE TVRD. Sličnost koja se ogleda u pružanju otpora omogućila je povezivanje pojma škrtosti sa pojmom tvrdoće, jer kao što svojstvo tvrdoće podrazumeva pružanje otpora proboju, na primer, sečiva, tako škrtost podrazumeva snažan otpor ka trošenju ili davanju novca ili čega drugog materijalne vrednosti. Otuda se u srpskom preterano štedljiva osoba opisuje kao tvrda. Možemo primetiti i to da se ovo metaforičko značenje u nekim primerima identifikuje na osnovu determinatora u vidu predloško-padežne konstrukcije na nečemu koja sledi pomenuti pridev (npr. tvrd na novcu). 
Tabela 10: Metaforički odnos BOGAT JE TVRD i značenje izvedeno na osnovu njega u semantičkoj strukturi prideva $t v r d$

10. BOGAT JE TVRD

- imućan, bogat (npr. tvrda kuća)

Bogatstvo se takođe poima pomoću pojma tvrdoće mada se može reći da je u ovom slučaju u središtu pažnje drugi aspekt mentalne slike tvrdog predmeta. Naime, tvrdoća je, kao svojstvo određenog objekta, rezultat čvrste zbijenosti čestica njegove unutrašnjosti, a upravo se na tome temelji i vizualizacija onoga što je bogato, i to kao objekta ispunjenog gusto zbijenim predmetima od vrednosti. Ovakva mentalna predstava uslovila je poimanje onoga što je bogato kao nečega što je tvrdo, pa tako govornici srpskog jezika za bogatu kuću, na primer, kažu da je tvrda.

\section{ZAKLJUČCI}

$\mathrm{Na}$ osnovu rezultata izvršene analize zaključuje se da je među svim pojmovnim metaforama aktiviranim u semantičkoj disperziji prideva hard i tvrd najviše onih koje su zajedničke za semantičke strukture ova dva prideva. Dakle, utvrđen je čitav niz apstraktnih ili manje konkretnih domena koji se konceptualizuju pomoću domena tvrdoće kako u engleskom, tako i u srpskom jeziku, a to su: domen napora (mentalnog ili fizičkog), snage (mentalne ili fizičke), emocija, pouzdanosti (istinitosti), postojanosti, intenzivnosti i izrazitosti karakterističnih svojstava. Povezivanje domena tvrdoće sa apstraktnijim domenom neprijatnosti (u fizičkom ili mentalnom smislu) karakteristično je samo za engleski jezik. S druge strane, samo se u srpskom jeziku bogatstvo, ali i štedljivost poima pomoću domena tvrdoće.

Metaforičko proširenje značenja data dva prideva zasnovano je na vizualizaciji tvrdog predmeta i isticanju određenog aspekta pojma tvrdoće kao fizičkog svojstva predmeta. Primarno istaknuti aspekt je otpornost na delovanje spoljnih sila koje nastoje da dati predmet oštete, deformišu ili unište. Ovaj aspekt je u engleskom i srpskom jeziku povezan sa različitim apstraktnijim domenima, a na osnovu tih veza u polisemičnim strukturama prideva hard i tvrd izvedena su značenja koja se odnose na: iziskivanje fizičkog ili mentalnog napora kao u slučaju napornog posla, mukotrpnog života, komplikovanog problema ili pitanja itd; fizičku i mentalnu izdržljivost animatnog subjekta; bezosećajnost ili emotivnu bezizražajnost osobe, njenog pogleda, glasa, lica, duše itd; pouzdanost, na primer činjenica, informacija, dokaza ili naučnog delovanja; postojanost odluka, namera, visokih cena $\mathrm{i}$ sl; izraženost karakteristične osobine nekoga ili nečega; jačinu 
delovanja opojnih sredstava i radijacije; škrtost osobe. Drugi aspekt istaknut prilikom proširenja značenja engleskog prideva je posledica fizičkog kontakta subjekta sa površinom tvrdog predmeta. Ovaj aspekt pojma tvrdoće povezan je sa domenom fizičke neprijatnosti, ali i mentalne neprijatnosti, pa su na osnovu tog metaforičkog odnosa izvedena značenja koja se odnose na neprijatnost izazvanu svetlošću, zvukom, nepovoljnim vremenskim prilikama, ali i uvredljivim rečima. Treći aspekt pojma tvrdoće istaknut u semantičkoj disperziji prideva $t v r d$ je čvrsta zbijenost čestica u unutrašnjosti predmeta koja mu i daje pomenuto svojstvo. Ovaj aspekt je povezan sa domenom materijalnog bogatstva, pa se otuda ono što je bogato, imućno opisuje kao tvrdo.

Predstavljena analiza je jasno ukazala $\mathrm{i}$ na to da pomenuti zajednički metaforički obrasci nisu jednako produktivni u semantičkoj disperziji prideva hard $\mathrm{i}$ tvrd. Štaviše, u slučaju pojedinih zajedničkih obrazaca, postoji značajna razlika u broju izvedenih značenja u dvema semantičkim strukturama.

Takođe, $u$ pojedinim slučajevima, na osnovu iste pojmovne metafore izvedena su potpuno različita značenja u strukturama dva prideva. To znači da ista konceptualizacija određenog apstraktnog pojma pomoću pojma tvrdoće može biti različito konkretizovana u engleskom i srpskom jeziku u zavisnosti od specifičnosti konteksta u kome se dati pridev upotrebljava ili referenta koji određuje.

Kao što je već istaknuto, analiza je pokazala da je značajan broj metaforičkih obrazaca aktiviranih u semantičkoj disperziji prideva hard i tvrd višestruko produktivan, odnosno u semantičkim strukturama oba prideva uočen je značajan broj slučajeva u kojima je nekoliko različitih značenja izvedeno na osnovu istog metaforičkog obrasca. Na osnovu ovog zapažanja zaključuje se i to da se polisemične strukture analiziranih prideva $\mathrm{u}$ velikoj meri temelje na skupu određenih pojmovnih metafora. Zapravo, može se reći da je analizirani deo datih polisemičnih struktura i organizovan prema ovim pojmovnim metaforama tako da je moguće uočiti grupe usko povezanih značenja izvedenih na osnovu istog pojmovnog obrasca, te koja su putem tog obrasca na isti način povezana sa osnovnim, doslovnim značenjem. Dakle, ovakva analiza metaforičkih značenja leksema omogućava detaljniji uvid u unutrašnju organizaciju njihovih polisemičnih struktura, a to saznanje bi moglo poslužiti kao osnova za drugačiju organizaciju rečničkih članaka, i to prema pojmovnim metaforama aktivnim u semantičkoj disperziji. Ovo bi korisnicima rečnika pružilo verniji prikaz međusobne povezanosti značenja i omogućilo lakše razumevanje metaforičkih značenja i njihovo memorisanje. 


\section{Ana Halas}

\section{METAPHORICAL SENSES OF THE ENGLISH ADJECTIVE HARD AND THE SERBIAN ADJECTIVE TVRD - A COGNITIVE LINGUISTIC ANALYSIS}

\section{Summary}

In this paper, there have been identified conceptual metaphors activated in the semantic dispersion of the English adjective hard and the Serbian adjective tvrd. The aim of the analysis has been to compare these metaphors and their productivity in the semantic structures of the two adjectives. Such a comparison has provided an insight into similarities and differences between English and Serbian related to the conceptualization of abstract notions using the notion of physical hardness as a source domain. The results of the analysis have shown that most of the identified metaphorical patterns are common for the two semantic structures in question. Actually, there is a range of abstract notions conceptualized on the basis of physical hardness as a source domain in both English and Serbian. However, the given common patterns are not equally productive in the two semantic structures. This means that there are cases in which there has been noticed a great difference in the number of senses derived on the basis of the same conceptual metaphor in the two semantic structures. What is more, it is a frequent case that completely different senses have been derived on the basis of the same conceptual metaphor in the semantic structures of the two adjectives. Therefore, the same conceptualization can be differently realized in the two languages depending on the context in which the given adjective is used. Finally, the observation that there are cases in which more than one sense has been derived on the basis of a single metaphorical pattern leads to the conclusion that the analysed polysemous structures are organized according to several conceptual metaphors. Hence, this analysis has provided a deeper insight into the internal organization of the polysemous structures of the adjectives hard and $t v r d$, which could be used as a model for the organization of dictionary entries according to conceptual metaphors activated in the semantic dispersion of a particular lexeme.

Keywords: polysemous structure, semantic dispersion, conceptual metaphor, metaphorical pattern, domain of hardness, metaphorical sense, English, Serbian.

\section{IZVORI}

Collins English Dictionary. Eleventh edition. Higgleton, E. (Ed.) Glasgow: Harper Collins Publishers. Available at http://www.collinsdictionary.com/ dictionary/english

Merriam-Webster Collegiate Dictionary. Eleventh edition. Mish, F.C. (Ed.) Springfield: Merriam-Webster Inc. Available at http://www.merriamwebster.com/

Metaphors Dictionary. (2001). Sommer, E. \& Weiss, D. (Eds.) Detroit: Visible Ink. Oxford Dictionary of English. Second edition. C. Soanes \& Stevenson, A. (Eds.) Oxford: Oxford Univesity Press. Available at https://www.oxforddictionaries.com/ 
Rečnik srpskohrvatskoga književnog jezika I-VI. (1967-1976). Stevanović, M. i dr. (ured.) Novi Sad, Zagreb: Matica srpska, Matica hrvatska. (Objavljeno ćirilicom!)

Rečnik srpskoga jezika. (2007). Nikolić, M. (ured.) Novi Sad: Matica srpska. (Objavljeno ćirilicom!)

Renton, N. E. (1990). Metaphorically Speaking. New York: Warner Books.

Wilkinson, P. R. (2008). The Concise Thesaurus of Traditional English Metaphors. London: Routledge.

\section{LITERATURA}

Bartsch, R. (2003). Generating Polysemy: Metaphor and Metonymy. In: Dirven, R. \& Pörings, R. (Eds.) (2003). Metaphor and Metonymy in Comparison and Contrast. Berlin, New York: Mouton de Gruyter. 49-74.

Cruse, A. (2011). Meaning in Language. An Introduction to Semantics and Pragmatics. $3^{\text {rd }}$ edition. Oxford: Oxford University Press.

Dragićević, R. (2010). Leksikologija srpskog jezika. Drugo izdanje. Beograd: Zavod za udžbenike. (Objavljeno ćirilicom!)

Evans, V. \& Green, M. (2006). Cognitive Linguistics. An Introduction. Edinburgh: Edinburgh University Press.

Gentner, D. \& Bowdle, B. (2008). Metaphor as Structure-Mapping. In: Gibbs, R.W.JR. (Ed.) (2008). The Cambridge Handbook of Metaphor and Thought. Cambridge: Cambridge University Press. 109-128.

Gortan-Premk, D. (2004). Polisemija i organizacija leksičkog sistema u srpskome jeziku. Beograd: Zavod za udžbenike i nastavna sredstva. (Objavljeno ćirilicom!)

Halupka-Rešetar, S. \& Radić-Bojanić, B. (2015). Polysemy of the Lexemes Home in English and dom in Serbian. Nasleđe, 32, 51-60.

Klikovac, D. (2004). Metafore u mišljenju i jeziku. Beograd: Biblioteka XX vek.

Knowles, M. \& Moon, R. (2006). Introducing Metaphor. London, New York: Routledge.

Komaromi, B. (2016). Sinestezijska metafora u pridevima u engleskom i srpskom jeziku: kognitivnolingvistički pristup. (Nepublikovana doktorska disertacija). Filozofski fakultet, Univerzitet u Novom Sadu, Novi Sad.

Kövecses, Z. (2010). Metaphor. A Practical Introduction. 2nd edition. Oxford: Oxford University Press.

Lakoff, G. \& Johnson, M. (1980). Metaphors We Live By. Chicago: University of Chicago Press. 
Lakoff, G. \& Johnson, M. (2014). O pojmovnoj metafori. U: Rasulić, K. \& Klikovac, D. (ured.) (2014). Jezik $i$ saznanje. Hrestomatija iz kognitivne lingvistike. Beograd: Filološki fakultet. 273-305. (Objavljeno ćirilicom!)

Prodanović-Stankić, D. (2009). Pojmovna metonimija i metafora u značenjima lekseme srce u srpskom jeziku. Godišnjak Filozofskog fakulteta u Novom Sadu, XXXIV-1, 77-87.

Radić-Bojanić, B. \& Halupka-Rešetar, S. (2014). Višeznačnost leksema door i window u engleskom i vrata i prozor u srpskom jeziku. U: Živačević Sekeruš, I. \& Majstorović, N. (ured.) (2014). Susret kultura. Zbornik radova. Novi Sad: Filozofski fakultet. 347-358.

Rakova, M. (2003). The Extent of the Literal. Metaphor, Polysemy and Theories of Concepts. New York: Palgrave Macmillan.

Stanojević, M. (2013). Konceptualna metafora. Temeljni pojmovi, teorijski pristupi $i$ metode. Zagreb: Srednja Europa. 